\title{
Gambling with COVID-19 Makes More Sense: Ethical and Practical Challenges in COVID-19 Responses in Communalistic Resource-Limited Africa
}

\author{
David Nderitu • Eunice Kamaara $(\mathbb{D}$
}

Received: 1 May 2020 / Accepted: 27 July 2020

(C) Journal of Bioethical Inquiry Pty Ltd. 2020

\begin{abstract}
Informed by evidence from past studies and experiences with epidemics, an intervention combining quarantine, lockdowns, curfews, social distancing, and washing of hands has been adopted as "international best practice" in COVID-19 response. With massive total lockdowns complemented by electronic surveillance, China successfully controlled the pandemic in country within a few months. But would this work for Africa and other communalistic resource-poor settings where social togetherness translates to effective sharing of basic needs? What ethical and practical challenges would this pose? How would communalism be translated in special contexts to be useful in contributing to the ultimate common good? This paper uses examples from the current situation of COVID-19 in Kenya to address these questions.
\end{abstract}

Keywords COVID-19 - International best practice . Africa $\cdot$ Communalistic resource-poor $\cdot$ Ethical and practical challenges

\section{Nderitu}

Egerton University, P.O. Box 536, Egerton, Rift Valley 20115, Kenya

e-mail: david.nderitu@egerton.ac.ke

E. Kamaara $(\bowtie)$

Moi University, P.O. Box 3900, Eldoret, Rift Valley 30100,

Kenya

e-mail: ekamaara@gmail.com

\section{Introduction}

Coronavirus disease (COVID-19) continues to spread. By mid-April 2020, total global infections stood at more than 1.7 million and deaths surpassed 100,000 (World Health Organization 2020b). In China, the initial epicenter of COVID-19, stringent confinement of people living in high risk areas slowed down the spread of the virus (Lau et al. 2020). Consequently, governments across the world have been enforcing lockdowns, quarantines, curfews, and social distancing (de Figueiredo et al. 2020) combined with public health advice to frequently wash hands with soap or alcohol-based sanitizers, to wear face masks, and to avoid touching one's face.

While a combination of these measures is being touted as "international best practice", these measures do not work in many African settings. In this essay we illustrate the practical and ethical challenges of each of these measures in communalistic resource-poor African settings and suggest a pragmatic paradigm in addressing the crisis in these contexts.

\section{Practical Challenges of COVID-19 Response in Africa}

COVID-19 assumed a slow pace in the initial phase of the spread in Africa until the end of March 2020 (Johns Hopkins 2020) when infections rose significantly. As of April 29, 2020 a cumulative total of 34,610 confirmed COVID-19 cases were reported in fifty-two out of the 
fifty-four African countries (no cases reported in Lesotho and Comoros) and 1,517 deaths were confirmed (WHO Africa 2020). With more than 50 per cent of the world's 700 million extremely poor people living in Sub-Saharan Africa (Singh 2020), the continent could see up to 450,000 people test positive for COVID-19 by mid-May (Merab 2020). Experience suggests otherwise. According to the Africa Centres for Disease Control and Prevention (Africa CDC), as of May 26, 2020 there were 115,346 COVID-19 cases and 3,471 deaths reported in the continent (Africa CDC 2020), representing approximately $2 \%$ of all cases reported globally. This phenomenon may be associated with Africa's characteristically youthful population (at most, $3 \%$ of the continent's population is less than 65 years of age), and its relatively low prevalence of hypertension and diabetes, conditions which may increase the risk of more severe COVID-19 infection. Notwithstanding, many African governments have adopted the "international best practice" to avert this (Agence France-Presse (Nairobi) 2020). But are these measures viable?

\section{Social Distancing}

Social distancing entails keeping physical distance between persons, avoiding large crowds, and not touching people if you don't need to (World Health Organization 2020a). But this is not practical in all settings.

In Sub-Sahara Africa, poor communities typically live in high-density shanty towns, with many family members sharing tiny spaces in makeshift shelters and communal homesteads, while millions more live on the streets (Singh 2020). "Stay-at-home" contradicts social distancing because many homes are much more crowded than streets or places of work.

The challenge of space is compounded by poverty and communalism, a core value and survival strategy in Africa where physical togetherness translates to effective sharing of basic needs especially in crises. For example, in an extended family where many nuclear families share a homestead, children eat in the house where the lunch hour finds them. If one nuclear family has no food, they send their children to the other house for meals and "sleep-overs". In such contexts, keeping social distance necessarily translates to hunger.

Moreover, in contexts where families cannot afford reliable sources of information, social distancing may be counterproductive. Close social ties may be the only way through which reliable information, in this case on COVID-19, is communicated.

\section{Quarantine}

Both self and forced quarantine of COVID-19 infected or suspected cases do control spread of the disease. However, the effectiveness of quarantine depends on how well it is implemented. In Kenya, as in many African countries, those facing mandatory quarantine have decried the pathetic conditions in government isolation centres. Hygiene is poor and people interact freely within the centres exposing those who are not infected to infection. Those forced into quarantine in hotels at their own cost decry exorbitant daily bills. Moreover, some are forced into quarantine without the opportunity to choose in what facility to isolate.

Worse still, sometimes people are forced into quarantine unnecessarily. In Kenya, for example, if one is found breaking any government measures against COVID-19, they are bundled together in police cars (exposing them to infection) and taken to isolation centres at their own cost. Similarly, those found in public places or socializing in private without face masks are forced into isolation centres regardless of whether they have signs of infection or whether they interacted with people who have tested positive for COVID-19.

Consequently, people are defying all efforts to quarantine. There are reports of people breaking away from forced quarantine, refusing to self-quarantine, or bribing their way out of isolation. Quarantine then works against its very purpose by becoming a weak link in COVID-19 prevention. It exposes people to infection and then incites them to go back into the broader community.

\section{Building Isolation Centres and New Hospital Wards}

Developed countries have responded to the COVID crisis by building special isolation centres and new hospitals. China built a one thousand-bed facility in less than two weeks. Other developed countries followed suit but not always with similar success. In the United States of America and Italy, for example, demand for COVID-19 management facilities continues to overwhelm supply.

These experiences send significant lessons to African countries whose healthcare systems are already overwhelmed by high disease burden, inadequate facilities, under-staffing, and lack of equipment among other 
challenges. African health systems have huge deficits of basic materials like testing kits, personal protective equipment, and equipment for assisted breathing (de Waal and Richards 2020). By mid-April, ten of the fifty-four African countries did not have a single ventilator (Maclean and Marks 2020). Others had one ventilator for almost every three million people-South $\mathrm{Su}-$ dan, with eleven million people, had only four ventilators (Ajack 2020).

African countries have to re-think strategies for COVID-19 prevention and management. Pragmatically, international best practices are almost guaranteed not to work. Borrowing money or begging for donations is not viable. Kenya, like many African countries, is already deep in international debts and grants, all of which come with "strings attached".

\section{Lockdowns}

Many African governments hurriedly implemented lockdowns when the COVID-19 outbreak hit their countries (de Waal and Richards 2020). Yet, lockdown strategies are disastrous in economically struggling contexts. For a majority of Africans who eat from hand to mouth and cannot afford to stock food even for two days, lockdown translates to starvation (Nderitu 2020). Unlike governments in developed countries, most governments in Africa could not afford to feed so many poor families sustainably and the risk of dependence after COVID-19 is real (De Waal and Richards 2020). COVID-19 is merely worsening a bad situation: before lockdown was implemented, some Kenyan families were already begging for food. With the familiar horror of starvation, gambling with COVID-19 with its relatively small mortality rate, (de Waal and Richards 2020) can make more sense.

\section{Personal Hygiene and Protection}

Experiences of abject poverty across Africa also raise questions about the practicality of use of face masks and personal hygiene strategies to prevent COVID-19 spread. First, at a cost of about one U.S. dollar, a mask is expensive for many families. To expect an average family of five living on less than a dollar a day to use five dollars for masks would be hilarious if it were not so tragic. Availability of locally made masks at half the price helps but it does not entirely address the challenge.
Second, despite efforts by public health experts to spread awareness on why and how to use masks, generally many people in Africa are not using masks or they are not using them properly. Governments have had to enforce use of masks by punishing those found in public spaces without masks. In Kenya, anybody caught without a mask in public is rounded up and taken to forced quarantine for fourteen days, at their own cost, after which they are charged with exposing fellow citizens to COVID-19 and fined heftily. This has effectively created fear among Kenyans, especially in urban areas, forcing them to use masks, but not without some backlash. As mentioned earlier in this paper, people are wearing masks to avoid being quarantined and fined rather than to protect themselves. Clearly, the punitive implementation of COVID-19 measures by African governments is criminalizing poverty rather than preventing and controlling COVID-19.

Poor use of masks in Africa is more likely to spread than prevent COVID-19. Used masks are treated like any other piece of cloth. For example, they are left carelessly on various surfaces, and they are worn for a week to be washed on weekends with other garments. Mostly, masks are not serving a protective purpose but are creating the wrong impression that wearing a mask is sure protection from infection-encouraging people to interact freely once they wear a mask.

Similarly, washing of hands from a running tap seems easy and affordable. However, to many Africans who barely have access to drinking water, using the little water they get to regularly wash hands would be careless. Many families, especially in urban areas, buy water for all uses.

\section{Ethical Challenges and Suggestions on COVID-19 Response}

Africans are clear about their moral obligation to prevent and control COVID-19 spread. However, African contexts present unique situations which call for contextualized responses. Ignoring these contexts raises ethical concerns.

Contrary to the dominant Western view of atomistic individuals who possess biological and psychological independence, African communalism conceptualizes persons as so integrated within a community that an individual cannot be defined apart from community. In other words, the existence and resilience of the individual, especially in the face of calamity, depends on the 
existence and resilience of community. This understanding informs the philosophical concept and practice of Ubuntu expressed by Mbiti 1969 thus: "I am because we are, and since we are, therefore I am". Communalism presupposes that the communal good is constitutive of the individual good, whereby the social norms of one's community guide and constrain individual motivation and agency (Gyekye 1997).

The most basic ethical principle, respect for persons, and the right to self-determination are breached when people are forced to do what is not in their interest. Yet, few infectious disease control measures would be imposed effectively without the consent and goodwill of the people affected. Lessons are rife from the Ebola epidemic in Liberia (de Waal and Richards 2020). Moreover, enforcing something in which people do not believe causes more harm than good. It raises issues of justice too. Already, human rights activists in Kenya have raised concerns that more people have died from police brutality in enforcing COVID-19 prevention than have died of the pandemic.

With poverty catalyzing indigenous communalism for resilience, measures such as total lock down, individual social distancing, quarantine, washing hands, and wearing masks and other COVID-19 "international best practices," pose practical and ethical challenges. "For people already suffering hardship because of unemployment, drought or a swarm of locusts, social welfare is provided by relatives. If a lockdown cuts these social ties, adversity becomes destitution" (de Waal and Richards 2020, "Why governments need to talk to the people," II6).

African governments have taken action to cushion citizens from the effects of COVID-19. Kenya has implemented a number of supportive measures such as tax relief for persons with low salaries, addition of relief funds for vulnerable citizens, and suspension of listing with Credit Reference Bureau (UNDP 2020). While such efforts are necessary, they do not have impact for persons who live on daily wages. Moreover, the efforts are limited given the economic overdependence of African governments on international economies that are currently under threat.

The pragmatic approach would be to urgently and innovatively harness African indigenous communalism for resilience. This calls for intensive community engagement to identify "grassroots best practices" and adapt them, informed by international best practices. For example: rather than isolate individuals, perhaps isolation of extended families would make more sense; rather than isolate cities, isolation of "hoods" in slums would make more sense; rather than build isolation and new hospital wards when the current ones are inadequate and don't have equipment and personnel, COVID-19 management in Africa might work best at community and family levels.

Previous experience with HIV, Ebola and other epidemics provide clear lessons. Key among these is that "a rapid, holistic and cohesive response from all arms of government, civil society and local communities is absolutely critical"(Payne 2020, 436). For communalistic resource poor settings, community engagement is most critical. "Doctors and epidemiologists can provide the medical facts, but communities can provide the contextual details and knowledge of what has worked (or still working) for them ..." (de Waal and Richards 2020, "Why governments need to talk to the people," I2). Pragmatic control of the COVID-19 would only be possible under combined effort and mutual respect.

\section{Conclusions}

With globalization and universal crises, particularly related to health like COVID-19, there is shared responsibility. However, regardless of global connectedness, mitigation approaches to real time challenges have to respect context. Africans have unique socio-cultural and economic landscapes as well as unique value frameworks.

In the context of COVID-19, lockdowns, "Stay at home" directives, and other "international best practices" would not work in resource-poor crowded settings where families live on daily wages. They would translate to hunger and social unrest as has happened in many parts across Africa, leading to more harm than good. While African governments have taken some action to cushion citizens from the effects of lock down, these efforts are grossly inadequate and unsustainable since the governments rely on international donor economies for economic assistance. With the COVID-19 pandemic crippling these donor economies, assistance would not be forthcoming to African governments.

But the situation is not all gloom. The African communalistic value framework is a resource that may be harnessed for effective contextualized response to and resilience in the face of COVID-19. This necessarily calls for intensive and extensive community engagement, adoption and adaptation of lessons from past epidemics, and coordinated efforts across sectors for contextualized holistic approaches. The slower pace of 
COVID-19 spread in Africa affords the continent the opportunity to strategize.

With COVID-19, resource-limited communitarian African contexts demand innovation, beyond "gold standard" or "international best practice," for practical and ethical utility. It is only in recognizing and respecting unique contexts that the fundamental "common good" becomes appropriate. Going forward, we propose intensive community engagement to provide practical and ethical responses to COVID-19 in Africa.

\section{References}

Africa Centres for Disease Control and Prevention. 2020. Outbreak Brief 19: COVID-19 Pandemic-26 May 2020. African Union Africa CDC. https://africacdc. org/download/outbreak-brief-19-covid-19-pandemic-26may-2020/ Accessed May 30, 2020.

Agence France-Presse (Nairobi). 2020. "Starve or get sick": Africa's lockdown dilemma. rfi, France Médias Monde, April 14. http://www.rfi.fr/en/wires/20200414-starve-or-getsick-africas-lockdown-dilemma. Accessed April 14, 2020.

Ajack, M. 2020. South Sudan becomes the 51st country in Africa with COVID-19 as it confirms its first case. Time, April 5. https://time.com/5815838/south-sudan-africa-coronaviruscovid-19/ Accessed on April 27, 2020.

de Figueiredo A.M., A.D. Codina, D.C.M.M. Figueiredo, M. Saez and A.C. Leon. 2020. Impact of lockdown on COVID-19 incidence and mortality in China: An interrupted time series study [Pre-print]. Bulletin of the World Health Organization. E-pub: April 6. https://doi.org/10.2471/BLT.20.256701. Accessed April 17, 2020.

de Waal, A., and P. Richards. 2020. Coronavirus: Why lockdowns may not be the answer in Africa. BBC News, April 15. https://www.bbc.com/news/world-africa-52268320 Accessed April 17, 2020.

Gyekye, K. 1997. Tradition and modernity: Philosophical reflections on the African experience. Oxford: OUP USA.

Johns Hopkins University and Medicine. 2020. Johns Hopkins Coronavirus Resource Center. https://coronavirus.jhu.edu/. Accessed April 1, 2020.

Lau, H., V. Khosrawipour, P. Kocbach, et al. 2020. The positive impact of lockdown in Wuhan on containing the COVID-19 outbreak in China. Journal of Travel Medicine, March 17. https://doi.org/10.1093/jtm/taaa037.

Maclean, R., and S. Marks. 2020. 10 African countries have no ventilators. That's only part of the problem. New York Times,
April 18. https://www.nytimes.com/2020/04/18 /world/africa/africa-coronavirus-ventilators.html. Accessed April 27, 2020.

Mbiti, J.S. 1969. African religions and philosophy. Nairobi: Heinemann.

Merab, E. 2020. 450,000 Africans projected to contract Covid-19 by May. The East African, April 5. https://www. theeastafrican.co.ke/news/ea/450000-Africans-projected-tocontract-covid19-by-may/4552908-5513978-3cc9tn/index. html. Accessed 27 April, 2020.

Nderitu, D. 2020. Coronavirus poses ethical concerns: A view on the choices being made in Kenya. The Conversation, April 22. https://theconversation.com/coronavirus-poses-ethicalconcerns-a-view-on-the-choices-being-made-in-kenya135338. Accessed April 23, 2020.

Payne, C. 2020. COVID-19 in Africa. Nature Human Behaviour 4: 436-437.

Singh, J.A. 2020. COVID-19: putting the poor and vulnerable on the radar. Epidemic ethics [blog], April 9. Public Health Emergency Preparedness and Response Ethics Network. https:/epidemicethics.tghn.org/community/blogs/post/258785 /2020/04/covid-19-putting-poor-and-vulnerable-radar/. Accessed April 17, 2020.

UNDP. 2020. Articulating the pathways of the socio-economic impact of the coronavirus (COVID-19) pandemic on the Kenyan economy. United Nations Development Program Policy Brief, Issue No. 4/2020. April. https://www.undp. org/content/dam/rba/docs/COVID-19-CO-Response/SocioEconomic-Impact-COVID-19-Kenya-Policy-Brief-UNDPKenya-April-2020.pdf. Accessed May 29, 2020.

World Health Organization. 2020a. Coronavirus disease 2019 (COVID-19). Situation Report-66. World Health Organization, March 26. https://www.who.int/docs/defaultsource/coronaviruse/situation-reports/20200326-sitrep-66covid-19.pdf?sfvrsn=81b94e61_2. Accessed April 20, 2020. - 2020b. Coronavirus Disease 2019 (COVID-19). Situation Report-83. World Health Organization, April 12. https://www. who.int/docs/default-source/coronaviruse/situationreports $/ 20200412$-sitrep-83-covid-19.pdf?sfvrsn=697ce98d_4. Accessed July 2, 2020.

World Health Organization Africa. 2020. African countries move from COVID-19 readiness to response as many confirm cases. World Health Organization Regional Office for Africa, April 29. https://www.afro.who.int/healthtopics/coronavirus-covid-19. Accessed April 30, 2020.

Publisher's Note Springer Nature remains neutral with regard to jurisdictional claims in published maps and institutional affiliations. 